\title{
Violencia contra la intimidad y la propia imagen desde la apología del delito en el periodismo
}

VIOLENCE AGAINST INTIMACY AND SELF-IMAGE FROM THE APOLOGY OF CRIME BY JOURNALISM

\section{Leonor Guadalupe Delgadillo-Guzmán*}

* Universidad Autónoma del Estado de México, México

Correo-e: delgadilloleonor (a) gmail.com

Recibido: 30 de abril de 2020 Aprobado: 8 de enero de 2021

Resumen: Se muestra la apología del delito que hace el periodismo pretextando el derecho a la libre expresión, a propósito del exceso de información sobre datos confidenciales personales que, al ser expuestos, detonan efectos adversos sobre la integridad de quien ha sido exhibido y sobre su derecho a la intimidad, al honor y a la propia imagen. El análisis se realiza desde el punto de vista de la ética, el derecho y la psicología. Se concluye que los medios de comunicación incurren en este tipo de conductas, que constituyen una acción delictiva tolerada socialmente en lo general y judicialmente en lo específico. En no pocos casos, a tal acto se le confiere un valor superior sobre la norma jurídica establecida para la protección de la integridad y salvaguarda de la persona atacada. En consecuencia, se identifica el principio de contradicción para activar la litis por parte de las víctimas y ofendidos desde la vía penal y civil.

Palabras clave: deontología; periodismo; comunicación de masas; ética de la comunicación; ética de la prensa; derechos humanos; derecho a la privacidad; libertad de expresión; fuente de información

Abstract: We exhibit the apology of crime of the right to free expression in relation to information excess regarding personal confidential data which by being exposed trigger adverse effects on the integrity of the individual exposed and transgress their right to intimacy, honor, and self-image. The analysis is carried out from law, psychology and ethics. It is concluded that communication media make an apology of crime that is itself a generally tolerated crime, however in specific, judicially. Oftentimes, such act is given a value over the juridical norm established for the protection of integrity and safekeeping the attacked individual. Consequently, the contradiction principle is identified so that litis is enacted from the penal and civil side by the victims and offended.

Keywords: deontology; journalism; mass communication; communication ethics; press ethics; human rights; right to privacy; freedom of expression; information sources 
L a apología del delito es entendida como toda expresión dirigida a las personas que manifiesta en su contenido el enaltecimiento de un crimen, de su autor o de ambos. Consiste en una incitación explícita a reproducir la comisión del delito que se exalta, en este caso, la exhibición de la vida íntima. Su naturaleza, entonces, es la provocación de una curiosidad mórbida colectiva. En México, ejemplos interesantes de esto son las narcoseries, producciones audiovisuales que describen la dinámica de la delincuencia organizada a nivel nacional e internacional, y que forman parte de la llamada narcocultura, alimentada por la prensa amarillista o la nota roja, que celebran corridos, vestimentas, modismos, entre otros elementos. Estos programas de entretenimiento cubren los criterios de tipicidad de la apología del delito, ya que son públicos y publicitados (Millán Martínez, 2017).

Otro referente inquietante lo constituye la apología del terrorismo, actos de violencia que en sí mismos constituyen un motivo suficiente para censurarse. En este sentido, se esgrime un interesante cuestionamiento en torno a si es legítimo sancionar el ejercicio de la libertad de expresión e información de este tipo de crímenes (SánchezOstiz, 2006).

Es indudable que cuando se encuentra comprometido un Estado ante un posible atentado, o bien por actos de delincuencia organizada, se debe privilegiar la seguridad sobre el derecho a la libre expresión, más aún en el contexto actual. A lo anterior se suma el efecto exponencial de las nuevas tecnologías, como internet. Los sitios web se usan cada vez más con fines propagandísticos y de incitación a la violencia por parte de terroristas, lo que brinda a estos grupos una gigantesca plataforma de cobertura mediática y hace urgente la cooperación internacional. El menú de recursos virtuales es amplio, mensajes contenidos en presentaciones, revistas, imágenes, videos, audios, juegos de video (Gadea Aldave,
2015: 87) se ven fortalecidos por los mecanismos de comunicación disponibles, foros, chats, correos electrónicos, Facebook, Twitter, YouTube. Ese mismo efecto se alcanza cuando los derechos personales son transgredidos.

En una dimensión personal y no institucional, la línea de diferenciación se torna tenue al tratarse de personas conocidas, públicas o notables, tales como políticos, artistas o deportistas. Esto queda claro en el caso de quienes se desempeñan en el ámbito político, ya que su privacidad se juega en el péndulo de lo que constituye una información sustantiva para la ciudadanía. La frontera entre su desempeño profesional y los actos de su vida personal se diluye y estos últimos terminan vinculados, directa o indirectamente, con el interés ciudadano (Gamboa Montejano y Ayala Cordero, 2007). Dicha condición se encuentra naturalizada en el mundo del entretenimiento. Dentro del periodismo de espectáculos, la intimidad de los artistas representa una oportunidad de venta para los medios de comunicación (Murcia González, 2010). El elemento común entre uno y otro tipo de celebridad es su impacto público, su visibilidad ante los miembros de una estructura social.

El límite de la libre expresión y el acceso a la información ha sido motivo de estudio (Millán Martínez, 2017, Sánchez-Ostiz, 2006; Gadea Aldave, 2015). Sin embargo, su relación con la dimensión de la privacidad resulta también relevante a la luz del consumo por parte de lectores de noticias escandalosas acerca de celebridades, cuya publicación resulta atractiva por el morbo que despierta. Lo anterior queda bien ilustrado en la emisión de revistas de espectáculos como TVyNovelas, que muestra cómo la lógica del mercado somete a los medios de comunicación a una competencia en la que, para sobrevivir, han de echar mano de elementos psicológicos de enganche, como la idealización, identificación y curiosidad de las personas con respecto a quienes son populares y objeto de su elección. 
Originalmente, el periodismo de espectáculos tenía definida su cobertura, el entretenimiento en los márgenes de las artes y el deporte, pero conforme transcurrió el tiempo, por motivos de instrumentalidad financiera, por no decir de rentabilidad, se buscó un nuevo mercado, el del escándalo como espectáculo. Todo aquello que tuviese que ver con la inmoralidad, el abuso, la perversión y la corrupción fueron sus nuevas banderas. La temática es la misma, la explotación de la necrofilia, esa dimensión humana definida por Fromm (1992) como un síndrome, un conjunto de signos y síntomas caracterizados por la disposición maligna de las personas a sentirse atraídas y atrapadas por lo decadente, sobre todo si proviene de una figura pública - independientemente de su procedencia, ya sea el deporte, la actuación o la política - de la que se exige una pulcritud ética y, por lo tanto, moral. Tal ideación psicológica proviene de la fantasía de asociar la popularidad con una forma de perfección e imperturbabilidad, en suma, una imagen supraterrenal, fuera de lo ordinario, pero que al fin y al cabo es susceptible de derrumbarse.

Este tipo de información noticiosa adquiere relevancia no solo desde las rutinas informativas en cuanto a cuestiones editoriales de formato, encabezado, tamaño de titulares, primera página, número de líneas y uso de imágenes, sino también porque conecta con esa subjetividad colectiva que desea atestiguar - aunque en realidad no atestigua nada, simplemente consume una nota que se articula con tal neurótico deseo - cómo se desploma una imagen mediática humana, convirtiéndose en referente de la realidad. Así, se abren múltiples canales que regurgitan la información, valiéndose de analistas, expertos, especialistas, ciudadanos, quienes alimentan un vaivén intersubjetivo que otorga una sobrevigencia al evento suscitado en torno a esa persona extraordinaria y que se juega entre lo sincrónico y lo asincrónico (Yelo Díaz, 2004).
Efectivamente, no solo las notas rojas venden, sino también las figuras públicas con sus 'caídas' propiamente humanas. Esta rutina alimenta un proceso comunicativo entre quien informa y un sector de la población, así se produce una interdependencia entre el medio y la persona lectora. Con ello, incluso puede dejar de ser relevante la veracidad de la información y se deja de cuestionar la comprobación de los datos (Yelo Díaz, 2004). Se gesta de esta manera un entimema periodístico: consumo seguro del lector de noticias decadentes $=$ éxito periodístico del medio, con lo que queda cancelada, para el caso que nos ocupa, la primera premisa, el escándalo de la vida de las celebridades.

Es interesante advertir, tal y como apuntan Rivera Rogel, Pereira-Fariña y Yaguache Quichimbo (2015) sobre las rutinas de producción de diarios, cómo aun cuando se ha dado el cambio de la impresión a lo digital, las dinámicas de trabajo y práctica profesional se han mantenido. El esquema tradicional no tuvo ninguna modificación sustantiva al migrar de la versión en papel a la electrónica, a pesar de esperarse una diferencia positiva en contenidos y análisis por tal transición al no existir la fuerte presión del tiempo para no retrasar el tiraje. A esta condición se suma la escasez de recursos humanos y su baja capacitación, lo que lleva a mantener como caldo de cultivo patrones pobres de investigación y de reflexión sobre lo que se publica.

Para Rodrigo de la Cadena (2019), el periodismo de espectáculos se desvirtuó desde hace varias décadas, cuando se priorizó el chisme, el morbo, el rumor, la ignominia y la intromisión rapaz en la intimidad, lo que dejó en una minoría prácticamente imperceptible a los profesionales realmente comprometidos con la crítica artística, cuyas colaboraciones cargan la etiqueta de que no venden. Con ello, se derrumba el papel de intermediario de la acción de todo profesional del periodismo, mediador entre los diferentes 
sectores sociales y los poderes y figuras públicas, porque en algunos casos se da la espalda tanto a los procesos de legitimidad y análisis de la noticia como a los derechos de privacidad de las personas. Se desnuda así la imagen cruda de una práctica generalizada que toma distancia de la objetividad para acercarse al impacto de la significación de lo que se construye como supuesta verdad (Stange Marcus y Salinas Muñoz, 2009).

Esta dinámica condujo a una crisis de desempeño ético de los periodistas, quizás valga decir, a una crisis de valores que da claros visos de ignorar toda responsabilidad moral y cívica (Murcia González, 2010). Dichas prácticas cuestionables se ven fortalecidas con la derogación de las figuras de difamación o injurias.

Frente a este debilitamiento ético emerge el fortalecimiento jurídico del ejercicio de la privacidad o intimidad, ya no únicamente se han de proteger los bienes materiales sino también los inmateriales. Los derechos que involucran la intimidad o privacidad, el honor y la propia imagen representan bienes personales inmateriales que directamente se interrelacionan con el derecho a la paz, a no ser molestado (Gamboa Montejano y Ayala Cordero, 2007).

No obstante, la definición o entendimiento de la privacidad resulta ambigua frente a una tendencia global de extimidad, es decir, hacer pública la intimidad, exponerla (Tello Díaz, 2013). Jiménez Quezada (2018) señala que el término ha sido ocupado en la investigación para asociarlo con el uso de redes sociales por parte de los adolescentes con el fin de exhibir su privacidad, hacerla visible y quizás hasta impersonal. Pfeffer Urquiaga (2000), por su parte, indica que cuando se trata de mostrar públicamente estos elementos se implica la decisión personal de hacerlo, por lo que el individuo exhibido tomará la decisión consciente y voluntaria a título personal de que así sea.

Llegados a este punto, resulta necesario aprehender los elementos que bien podrían definir la intimidad. Pfeffer Urquiaga (2000) retoma la doctrina italiana que distingue cuatro diferentes dimensiones, la soledad, la intimidad, el anonimato y la reserva. La soledad implica la anulación de contacto físico con las personas. La intimidad involucra el reconocimiento de relaciones con estrecha distancia social. El anonimato comprende el ocultamiento de la propia identidad en relación con ciertos eventos o situaciones. Por su parte, la reserva engloba la cautela de las personas para mantener en silencio información que tienen bajo su conocimiento.

Con base en lo anterior, se está en posibilidad de visualizar cuáles son las acciones transgresoras sobre la intimidad: irrumpir la soledad sin anuencia; divulgar información personalísima sin consentimiento, valiéndose de una estrecha relación de confianza y amistad; destapar el anonimato asumido de quien decidió mantenerse oculto, incluso hasta llegar a la deformación de datos en combinación con la identidad de aquel que se descubre; revelar la discreción emprendida por alguien para mantener en silencio cierta información; así como usurpar la identidad de la persona por intereses y provechos personales desleales (Pfeffer Urquiaga, 2000).

Los criterios judiciales para sancionar estas conductas son diversos: partir de la notoriedad del transgredido; aquilatar las condiciones de lugar, tiempo y circunstancia; considerar el ataque perpetrado, o bien, atender a las características del agresor. Esta partición de componentes hace que para los juzgadores y personas en general sea difícil entender la magnitud del daño que se puede hacer a los afectados. En realidad, se debería optar por la integración de todos los elementos. Es interesante cómo se arguye que, en la medida en que alguien es una figura pública, su derecho a la intimidad no solo se ve limitado, sino es que obstruido, lo que resulta contradictorio cuando se habla del ejercicio y protección de los principios fundamentales, de los que la privacidad forma parte.

Tal planteamiento esgrime el sofisma de que entre más popularidad menos intimidad y, en consecuencia, el derecho a la privacidad se ve 
cancelado. Por su parte, los derechos fundamentales tienen como aforismos el que no son negociables, transferibles, prescriptibles, particulares, divisibles, no se pueden violar, no son renunciables ni opcionales.

Es aquí donde los medios de comunicación se incorporan como terceros con la obligación de acatar una actitud de respeto junto con las figuras normativas existentes para la protección de la intimidad como un bien y derecho personal. Esto se encuentra jurídicamente respaldado a nivel internacional por la Declaración Universal de Derechos Humanos (UN Human Rights, 1948); el Pacto Internacional de Derechos Civiles y Políticos en su artículo 17 (UN Human Rights, 1966); y la Convención Americana sobre Derechos Humanos, en su artículo 11. Protección de la Honra y de la Dignidad (OEA, 1969).

El problema que presentamos puede analizarse desde el modelo ecológico. Esta tesis plantea entender la sociedad como un elemento seriado de estructuras susceptibles de ser abarcables como sistemas que guardan una distancia particular con los individuos, las cuales se activan por la interrelación existente y por lo tanto dinámica entre tales sistemas y ellas (Bronfenbrenner, 1987; Pérez Fernández, 2004; Torrico Linares, Santín Villariño, Andrés Villas et al., 2002). En el ciclo vital completo infancia-adultez, el nivel más cercano es el microsistema, la familia y la escuela. Conforme se crece, los ambientes de participación aumentan y se interrelacionan, el vecindario, el trabajo, centros recreativos. El siguiente nivel es el mesosistema.

El marco de influencia de los sistemas ambientales no se agota ahí, existen otros en los que no participa el sujeto y de los que invariablemente es receptor potencial, por ejemplo, los centros de trabajo, hospitales, redes sociales, o bien, los medios de comunicación masiva, este es el llamado exosistema. Sobre él se encuentra el macrosistema, el más distante al individuo, en donde se mueven, modifican y mantienen elementos culturales con su correspondiente carga histórica, como los derechos humanos y su progresividad, la ética o ideologías, corrientes políticas, religiosas o artísticas.

En este modelo psicosocial, los derechos humanos se ubican dentro del macrosistema, se trata de una perspectiva teórico jurídica que implica sistemas particulares alejados de los individuos, esto es, marcos normativos jurídicos vigentes. Junto a ellos se encuentran los poderes fácticos del Estado, ejecutivo, legislativo y judicial, con las facultades que cada uno de ellos tiene en su haber.

Tener presente los marcos normativos conlleva el reconocimiento de los derechos humanos (Amnistía Internacional, s/f), que son universales, inalienables, irrenunciables, intransferibles, imprescriptibles e indivisibles, propios de la dignidad de la persona. Aluden a la libertad, igualdad, seguridad, participación en lo político, así como al bienestar social, cuyo impacto es directo sobre el desarrollo integral e íntegro del individuo. Entre sus objetivos centrales se encuentra el redimensionamiento del ejercicio del poder, de lo vertical a lo horizontal, para reducir las brechas de desigualdad, exclusión y prácticas discriminatorias (Borja Segade, García Varela e Hidalgo Lorite, 2011). Lo anterior empuja a la revisión del ejercicio ético del periodismo, más aún cuando, como se ha visto, los contenidos de los medios de comunicación masiva, particularmente los informativos y de entretenimiento, tienen impacto sobre las personas.

En tal sentido, Martínez Sánchez (2016) apunta que la noción de responsabilidad social del llamado cuarto poder es reciente, solo hasta la última década del siglo XX algunos medios asumieron el ejercicio de un código deontológico cuya posibilidad encierra la autorregulación informativa. Sin embargo, esto no logra alcanzarse, de acuerdo con Martínez Sánchez (2016), 
por diferentes razones, como la corrupción, los conflictos de interés, la espectacularización de la noticia y el desempeño de los periodistas.

Pese a ello, los esfuerzos por establecer claramente las tareas y objetivos sustantivos de la acción de los medios han sido expuestos por organismos internacionales, tal es el caso de la United Nations Educational, Scientific and Cultural Organization (Unesco), que señala:

1. El derecho del pueblo a una información verídica; 2. Adhesión del periodista a la realidad objetiva; 3. La responsabilidad social del periodista; 4. La integridad profesional del periodista; 5. Acceso y participación del público; 6. Respeto de la vida privada y de la dignidad del hombre; 7. Respeto del interés público; 8. Respeto de los valores universales y la diversidad de las culturas; 9. La eliminación de la guerra y otras grandes plagas a las que la humanidad está confrontada (1983: s/n).

Destaca, en relación con el objetivo aquí planteado, el derecho de la ciudadanía a una información verídica, cuestión que se ve obnubilada en el periodismo de espectáculos o amarillista. Ocurre, por ejemplo, que algunos medios no cotejan lo declarado por sus fuentes, a fin de lograr el criterio de verificabilidad de triangulación para constatar lo referido en las versiones de los informantes(Murcia González, 2010). Esta omisión muestra el desapego a los principios éticos que rige a los comunicadores de este tipo de notas, pero también reduce su papel a meros organizadores de descripciones relatadas en lugar de mostrarlos como indagadores exhaustivos que investigan la veracidad de un suceso. Es claro que no solo la dimensión ética es necesaria como un elemento regulatorio de la acción informativa, sino también la dimensión jurídico-legal.

Al conectarse el periodismo con la teoría psicosocial ecosistémica es fácil identificar que se trata de prácticas que se mueven a nivel macrosistémico, porque el individuo ccomún que consume tales contenidos carece de posibilidades para incidir en tal sistema $\mathrm{y}$, al mismo tiempo, se ve impactado por los efectos colectivos que este detona social y psicológicamente. Esto es más notorio en el caso de aquellas notas que, valiéndose de la notoriedad de una personalidad pública pueden, con la información íntima que divulgan, provocar consecuencias adversas y directas que comprometen o ponen en peligro la integridad, salud física y mental del sujeto, pues tales contenidos son colocados como el motivo de la espectacularización. Estos efectos pueden fundarse y motivarse únicamente si se ve comprometido el interés y bienestar de la ciudadanía como colectividad afectada por la acción del individuo, es el caso del peculado, la malversación de fondos, el tráfico de influencias, el fraude y la corrupción.

Divulgar en exceso información íntima de particulares con cierta notoriedad representa una apología del delito que busca justificarse con el ejercicio de las libertades de expresión e información y, potencialmente, puede llevar a la figura de un acto preparatorio del delito. Esto coloca en el ojo del debate los márgenes a los que debe estar sujeta la libertad de expresión, sobre todo cuando se advierte el derecho de las personas a la no incitación del odio y a la no trasgresión de su intimidad e imagen (Sánchez-Ostiz, 2006). Dicha situación establece un dilema entre garantizar que los individuos puedan articular sus opiniones e ideas sin temor a represalias y proteger la privacidad de terceros que son o pueden verse afectados en el proceso.

El derecho a la libertad de opinión y expresión se señala en el artículo 19 de la Declaración Universal de Derechos Humanos, la cual contempla, además, el no ser molestado por las propias opiniones y poder difundirlas más allá de cualquier frontera y medio del que se disponga (UN Human Rights, 1948). Por otro lado, el derecho de la persona a no ser víctima de cualquier injerencia 
arbitraria en su vida privada, su familia, domicilio o correspondencia, o bien, de ataques a su honra o reputación, debe ser protegido por la ley, como lo establece el artículo 12 de la Declaración Universal de Derechos Humanos (UN Human Rights, 1948).

Dicho lo anterior, se pensaría que se trata de un callejón sin salida, sin embargo, el artículo 29 de la misma declaración ayuda a equilibrar el ejercicio y protección de los derechos mencionados. Comencemos por las obligaciones que el individuo tiene hacia la comunidad, porque en ella se desarrolla y vive la libertad, en consecuencia, está sujeto a las limitaciones establecidas por la ley, cuyo contenido busca garantizar el reconocimiento y el respeto a los derechos de los demás, al tiempo de satisfacer las justas exigencias de la moral, el orden público y el bienestar general en el marco de una sociedad democrática. La anterior apreciación es compartida por la Universidad Nacional Autónoma de México (Instituto de Investigaciones Jurídicas, s/f). La Constitución Política de los Estados Unidos Mexicanos, en su artículo $6^{\circ}$, indica:

La manifestación de las ideas no será objeto de ninguna inquisición judicial o administrativa, sino en el caso de que ataque a la moral, los derechos de terceros, provoque algún delito, o perturbe el orden público; el derecho de réplica será ejercido en los términos dispuestos por la ley (DOF, 2020a: 11).

Justo ahí se encuentra el límite o, en otras palabras, el margen del ejercicio del derecho a la libre expresión. De esta forma, se reconoce la complejidad de la estructura generalizada de las sociedades contemporáneas, compuestas por una diversidad de colectividades que presentan su propio conjunto de valores, ideas, creencias, y que en algunos casos llegan a posturas dogmáticas y de clara intolerancia a otros grupos, con lo que fácilmente se activa la exclusión, la restricción y la preferencia. En consecuencia, los medios de comunicación están forzados a desalentar el encono y la polarización social en contra de figuras públicas que, no por serlo, dejan de tener derechos humanos. En opinión de quien esto escribe, en esta misma tesitura se encuentran las redes sociales, también obligadas a desalentar expresiones de odio.

En la constitución y en la Declaración Universal de Derechos Humanos asoma explícitamente lo establecido sobre los límites del manejo de la información. Además, la carta magna apunta que toda información, al menos en los medios, deberá ser imparcial, objetiva, oportuna y veraz, lo que significa que no se sesgarán los contenidos por elementos ideológicos, prejuicios, estereotipos o etiquetas engañosas, lo que a la luz de la realidad resulta no atendido.

En el mismo orden de ideas, el artículo $7^{\circ}$ del mismo marco normativo advierte sobre la inviolabilidad de la libertad a difundir opiniones, información e ideas, derecho que no se puede restringir. Para que se presente o lleve a cabo la censura se tienen previstos los límites señalados en el artículo $6^{\circ}$ del mismo ordenamiento. El artículo $7^{\circ}$ cancela cualquier ejercicio de censura previo (UNAM), a ello se añade la opacidad sobre cómo se ha de entender el ataque a la moral, a la vida privada, al derecho de terceros, la incitación de un delito o la perturbación del orden público.

El Código Penal Federal mexicano establece, en su artículo 207, que la apología del delito consiste en toda provocación a un delito, la apología de este o de algún vicio y la omisión de impedir una acción que atente contra el libre desarrollo de la personalidad, la dignidad humana o la integridad física o mental (DOF, 2020b: 108). En el artículo 208 se indica que a todo el que provoque la comisión de un delito sin que se lleve a cabo se le aplicará la sanción señalada, y de realizarse se le castigará como participante de este. Tal figura, indiscutiblemente, es replicada por las entidades federativas de México, por ejemplo, el Código 
Penal del Estado de México, capítulo V, artículo 211 (Gobierno del Estado de México, 1999).

Esta tipicidad del delito se ve reforzada por tres figuras: la calumnia, la difamación y la injuria, que ya fueron derogadas en el Código Penal Federal mexicano (DOF, 2020b). En términos objetivos, bien puede retomarse la premisa de que la licitud de los límites a la libertad de expresión se concreta cuando se activa el peligro de un interés fundamental del Estado, o bien, ante la amenaza del derecho de un particular. La UNAM aplica dicho planteamiento para periodos electorales o posicionamientos políticos que induzcan el voto de la ciudadanía, sin embargo, vale también para lo que respecta a particulares comunes o con cierta notoriedad pública por tratarse igualmente de sujetos de derecho.

De esta forma, se vuelven susceptibles de ser interrumpidos los ataques a la moral, a la vida privada o a terceros, ya sea que se trate de expresiones denostadoras que comprometan la imagen social de un particular o institución, o que alienten el rechazo o hasta el odio. Huelga decir que el contrapeso a esto es la dignidad, valor favorable e intrínseco a las personas.

Dicho lo anterior, se puede entender cómo la opinión pública, ante singularidades y eventos humanos, al tomar la dirección del rechazo activa una o varias expresiones discriminatorias y de forma sutil e inicial va violentando uno o múltiples derechos de la persona o entidad que ha sido denostada (INADI, s/f). Entender lo anterior permite evitar cualquier relativismo o interpretación subjetiva y favorece que se pueda exigir la protección de quien ha sido atacado.

De este modo, es dable entender que la discriminación es una forma de violencia que ataca la dignidad y la igualdad, y que se objetiva en la realidad de la vida cotidiana como un ordenamiento social, cuya tipicidad se caracteriza por contenerse en diferentes mecanismos, como distinguir, excluir, restringir o preferir. No es poco común encontrar que los términos 'normalidad' y 'costumbre' son cobijos y artilugios con los que se busca sostener y legitimar la discriminación. Ambos términos se construyen socialmente por la repetición generacional de un conjunto de creencias idealizadas carentes de sustento racional, cuya base no es otra que un modelo impuesto a seguir y, por lo tanto, reproducir, lo que es aprovechado como alimento de malas prácticas dentro del periodismo.

En la discriminación no existe un cuestionamiento al sistema de creencias, solo su defensa en perjuicio de aquellos que se desvían y dejan de apegarse a lo acostumbrado, de acuerdo con los escándalos que se les imputan. Lo anterior abre la puerta a la intolerancia y su normalización, y activa los mecanismos ya referidos, basados en prejuicios y estereotipos binarios reduccionistas y tendenciosos de distinción-no distinción, exclusión-inclusión, restricción-no restricción, preferencia-no preferencia, que al ser azuzados por noticias no del todo argumentadas, carentes de credibilidad y fundamentación legal, dan lugar a apologías del delito.

$\mathrm{El}$ ataque moral se encuentra ligado al atentado a la vida privada, una acción de este tipo revela el incumplimiento por parte de quien lo perpetra de su deber de respetar al prójimo. Con tal acto se compromete la honorabilidad del agredido, se afecta su calidad moral, su credibilidad de desempeño decente y la compostura respetuosa que asume frente a las normas sociales compartidas de forma general.

La dimensión moral de un individuo representa un bien altamente personalísimo que se sostiene en valores ideales de la estructura social que, al ser dañada, altera la reputación, el prestigio y el propio valer del sujeto señalado, desestabiliza su conciencia y autoestima, y puede generar trastornos psicológicos de alto costo.

Recibir un ataque de este tipo implica una transgresión a la privacidad, porque se trata de sucesos que no son de incumbencia pública y que al ser exhibidos producen consecuencias 
desfavorables difícilmente cuantificables. La intimidad involucra situaciones de la vida privada que exclusivamente se reservan para sí. Se trata del "derecho a que ciertos aspectos de nosotros mismos no sean conocidos por los demás, es una especie de derecho al secreto, a que los demás no sepan lo que somos, lo que sentimos y lo que hacemos" (Luis García San Miguel, en García Fernández, 2011: 27).

Este tipo de acciones afecta a la propia imagen, representa un constante riesgo para las figuras públicas y, dado su perfil, se convierte en una fuente rentable para los medios de comunicación. Habrá que acotar que las celebridades lo son de acuerdo con cierta dimensión social, ya sea política, económica, jurídica, artística, deportiva o religiosa. Solo se justifica la divulgación de información personalísima cuando, como ya se ha dicho y vale la pena repetir, esta afecta la dimensión social en la que tal figura influye y, por sus efectos, compromete el bien público o algún derecho fundamental de las personas (Gamboa Montejano y Ayala Cordero, 2007).

Como se ha podido constatar, los ataques a la privacidad y a la propia imagen se encuentran interrelacionados. Es difícil pensar que una dimensión resulta ajena a la otra cuando se trata de derechos personalísimos. Su contraste estriba en que la intimidad es interior, y la propia imagen, exterior, vinculada a aquellos elementos informativos de la personalidad que son de acceso público con base en las funciones que en términos sociales desempeña el individuo.

Proteger la propia imagen implica filtrar los permisos de uso totales o parciales que se hacen de ella. Cuando estos límites no son establecidos, constituye una práctica desleal de abuso y distorsión hacerla pública sin el consentimiento del involucrado (Pfeffer Urquiaga, 2000), lo que conlleva el riesgo de alentar la animadversión hacia la persona por parte del público que ha consumido tal información.

Podría pensarse, en términos jurídicos, que la línea restaurativa de la justicia hacia la víctima es suficiente para contrarrestar los daños ocasionados, sin embargo, esto está en tela juicio, puesto que no existe una medida objetiva para evaluar los perjuicios producidos a su existencia como individuo, a su vida privada como miembro de una familia, y a su entorno laboral y social. Ahora más que nunca las figuras públicas o con cierta influencia, como profesores, médicos, jueces, fiscales, se encuentran en el filo de la navaja respecto al manejo de su propia imagen y está en juego su integridad.

Estas experiencias, desde el nivel microsistémico, constituyen potenciales eventos traumáticos por los factores de riesgo que engloban, así como por la comorbilidad con el cuerpo y su evolución clínica. En términos psicológicos, nos enfrentamos al trastorno de estrés postraumático (TEPT). Se habla de trauma porque se trata de un acontecimiento invasivo de gran impacto emocional por la divulgación que lo caracteriza y por el contenido que comprende, susceptible de producir toda una sintomatología física y mental (Carvajal, 2002). En el caso que nos ocupa, el trauma es ocasionado deliberadamente por los periodistas que generan la nota escandalosa en contra de la persona y su actuar, motivo central de la información.

El impacto sobre el individuo objeto del escándalo puede durar días, semanas o meses. Incluye malestar generalizado, confusión, recuerdos recurrentes del evento, pesadillas catastróficas, incluyendo algunas sobre el acontecimiento, estupor, ansiedad, estados extremos de hiperalerta con hipersensibilidad, insomnio, sentimiento de desamparo, conductas disociadas, uso y abuso de alcohol y drogas, embotamiento para poder responder adecuadamente al medio externo, disminución del rendimiento o interés por las actividades, constricción emocional, extrañeza de sí mismo y de los demás, alteraciones en los procesos superiores del pensamiento, memoria, atención, y un rechazo a las actividades que puedan ligarse al hecho traumático, todo lo cual favorece el deterioro social, laboral e interpersonal. 
Dos de los grupos básicos de sucesos traumáticos de acuerdo con el DMS-IV son: la amenaza a la propia integridad, en este caso, de la víctima cuya intimidad e imagen es divulgada en los medios, y la amenaza a la integridad de otras personas, es decir, los ofendidos (Carvajal, 2002). De tal suerte, un juez que enfrente una demanda por daño moral o incitación al odio o discriminación debido a la inclinación sexual, por decir lo menos, deberá concentrarse en la severidad del evento, duración y frecuencia, no solo de la parte que emite el ataque sino también de quien lo sufre.

En el DMS-5, el TEPT (Psicoterapeutas.com, 2016) en general mantiene los mismos criterios y el cuadro se estructura de forma pormenorizada con énfasis en los síntomas disociativos de despersonalización, que consisten en un sentimiento de extrañamiento del sí mismo, así como desrealización, en la cual el individuo experimenta un sentimiento de irrealidad del entorno, como si viviese un sueño. También se pormenorizan los efectos desfavorables en la dimensión emocional, cognitiva, social y vital.

Pfeffer Urquiaga (2000) apunta que con la justicia restaurativa se cuenta con vías de resarcimiento de los daños con base en compensaciones monetarias como figura de indemnización; acciones reparatorias públicas como la réplica, la retractación y la disculpa; o bien, medidas cautelares. Estas vías, que a decir del autor y de quien esto escribe no son excluyentes, no agotan la multidimensionalidad de la aplicación integral de la justicia, porque es necesario que, en los procesos judiciales en los cuales se amenaza la integridad de la persona con motivo de ataques a su intimidad e imagen, el juez vigile la restauración integral de la víctima o posibles ofendidos, la sanción exhaustiva al agresor, así como la dinámica, impacto y consecuencias a corto, mediano y largo plazo del daño perpetrado.

Ataques a la imagen y a la intimidad se cuentan en el orden internacional y nacional.
Recordemos, por ejemplo, la infidelidad que cometió el príncipe Carlos de Inglaterra con Camilla Parker-Bowles, escándalo mediático que dio lugar a su divorcio de la princesa Diana de Gales, al que siguió la trágica muerte de esta. El afamado George Michael, por su parte, mantuvo su orientación sexual en privado hasta que fue captado por un paparazzi en la ciudad de Los Ángeles. El cantante pop entró a unos baños públicos seguido de un hombre al que se le insinuó y que resultó ser un policía. Del mismo orden es la inesperada aventura de Bill Clinton, expresidente de Estados Unidos, con una becaria, Mónica Lewinsky, relación sexual que lo llevó a juicio y cuyos efectos perjudicaron al partido demócrata. Paris Hilton fue otra relevante figura estadounidense cuya intimidad sexual fue grabada y divulgada sin su conocimiento por una expareja ( $\mathrm{S}$ Moda, 2019).

En México, algunas personalidades con cierta notoriedad pública han sido también motivo de escándalos mediáticos. Vicente Fernández, famoso intérprete de la canción ranchera, fue acusado de homófobo al revelarse que rechazó un trasplante de hígado por temor a que el donante fuese homosexual o drogadicto. De manera similar, el conocido actor Sergio Goiry fue objeto de escarnio al divulgarse un video en el que califica a la protagonista de la película Roma de india, además de afirmar que no merecía ser nominada a los óscar. Aunque se disculpó, se dice que desde entonces no ha trabajado en proyectos artísticos. El exmandatario Enrique Peña Nieto tampoco ha escapado a este tipo de eventualidades, pues fue acusado de sostener una relación cuando todavía estaba casado con quien fuera la primera dama, Angélica Rivera (Roldán, 2019).

Estas noticias amarillistas contrastan con aquellas en las que, efectivamente, figuras públicas han incurrido en actos de corrupción y, en algunos casos, levantan la sospecha de mantenerse impunes por inadecuados procedimientos judiciales. Como ejemplo de esto se tiene al 
exgobernador de Quintana Roo, Roberto Borge, acusado de daño patrimonial al haber vendido predios propiedad del Estado a bajo precio y realizar transacciones con recursos ilegales. Por su parte, el exgobernador de Nayarit, Roberto Sandoval, fue culpado de enriquecimiento ilícito y desvío de dinero. El congreso local autorizó su enjuiciamiento por presuntas violaciones graves y lo inhabilitó por más de diez años (Alvarado, Ramírez, Ortiz et al., 2018).

El exgobernador de Tamaulipas, Eugenio Hernández, fue acusado por una corte federal del Estado de Texas por asociación delictuosa, fraude bancario y lavado de dinero, delitos que apuntan a un enriquecimiento ilícito (Alvarado, Ramírez, Ortiz et al., 2018). Algo similar se registra en la renuncia presentada por Eduardo Medina Mora, quien se desempeñaba como ministro de la Suprema Corte de Justicia de la Nación, tras darse a conocer que llevó a cabo transferencias bancarias internacionales por 103 millones de pesos en cuentas registradas a su nombre en Estados Unidos, Gran Bretaña y México, monto detectado por la Unidad de Inteligencia Financiera que superaba sus ingresos declarados. Su comportamiento, desde la óptica de la Fiscalía General de la República, obedece al delito de lavado de dinero (Ramírez Aguilar, Ortiz Monasterio, Núñez González et al., 2019).

Es indiscutible la necesidad de que se divulguen estos excesos que van en detrimento del erario y del pueblo mexicano, cuyos efectos nocivos laceran la solvencia de las arcas del Estado $y$, en consecuencia, ponen en riesgo la suficiencia de recursos de los planes de desarrollo estatales y federales. También urge demandar el acceso transparente, igualitario y expedito a la justicia, además del establecimiento de una legislación progresiva, objetiva, en beneficio de la ciudadanía y no de grupos con intereses particulares. Todo lo anterior se juega en el macrosistema con efectos en el microsistema de las personas, y sus alcances tienen efectos nocivos en las políticas públicas y programas de bienestar social.

\section{CONCLUSIONES}

1. Los medios de comunicación incurren en una apología del delito que constituye una acción delictiva tolerada socialmente en lo general y judicialmente en lo específico, como lo confirman los casos ejemplificados.

2. El retorno a un ejercicio ético y justo por parte de los periodistas es responsabilidad a título personal, como también de sus editores, cuya obligación es respaldar, corregir, o bien, adaptar sus contenidos en apego a las reglas vigentes respectivas.

3. La apología del delito que efectúan los medios de comunicación contra particulares públicos y no públicos debe ser examinada por los juzgadores desde las diferentes dimensiones básicas que implica, la víctima, los ofendidos, el agresor o agresores, junto con las características de la ofensa.

4. La protección a la intimidad no debe usarse como moneda corriente de los medios de comunicación para el consumo de lectores ávidos de noticias amarillistas que comprometen la integridad de particulares.

5. Debe pugnarse por el ejercicio ético de la acción periodística junto con la protección de la imagen e intimidad personal del individuo, cuyo límite está establecido por la salvaguarda del derecho legítimo a velar por los intereses de quienes conforman el pueblo, lo que se traduce en la vigilancia y examen exhaustivo de las figuras públicas y no públicas como responsables de un bien depositado para y en favor de la ciudadanía.

6. Es necesario divulgar las malas prácticas por las que optan algunos periodistas 
$\mathrm{y}$ editoriales que ponen en entredicho y en peligro la integridad psicosocial de los particulares y terceros interesados, para que los receptores sepan qué hacer y con quién dirigirse al respecto de los excesos cometidos por los medios de comunicación.

7. Se torna necesario reflexionar sobre el alcance de las sanciones y prevenciones a tomar para garantizar la protección de las personas que han sido afectadas por este tipo de apología del delito, así como la no reincidencia por parte del agresor, lo que puede significar actualizar la norma con el aumento de las penas contempladas.

8. Las disculpas públicas como medida restaurativa deberán tener el mismo alcance viral que la divulgación de la noticia que comprometió la integridad e imagen de la víctima y de los ofendidos. En caso de existir dudas por parte del juzgador, y dada la dificultad para evaluar objetivamente los daños, tendrá que considerar una extensión mayor en medios y en tiempo respecto a la noticia divulgada, amén de la indemnización económica.

\section{REFERENCIAS}

Alvarado, Ricardo, Sofía Ramírez, Leonor Ortiz et al. (2018), "Anuario de la corrupción 2018", en Nexos, 17 de diciembre de 2018, México, disponible en: https://www.nexos. com.mx/?p=40511

Amnistía Internacional (s/f), "Características de los Derechos Humanos", disponible en: http://www.amnistiacatalunya. org/edu/es/historia/dh-caracteristicas.html

Borja Segade, Carmen, Paloma García Varela y Richard Hidalgo Lorite (2011), El enfoque basado en Derechos Humanos. Evaluación e Indicadores, Madrid, Red EnDerechos, disponible en: https:/www.aecid.es/Centro-Documentacion/ Documentos/Evaluaci\%C3\%B3n/EvaluacionEBDH\%20 $+\% 20 \mathrm{NIPO}+\% 20$ logo.pdf

Bronfenbrenner, Urie (1987), La ecología del desarrollo humano, Barcelona, Paidós.

Carvajal, César (2002), "Trastorno por estrés postraumático: aspectos clínicos", Revista Chilena de Neuro-psiquiatría, vol. 40, spl. 2, disponible en: https:// scielo.conicyt.cl/scielo.php?script $=$ sci_arttext\&pid $=$ S0717-92272002000600003
De la Cadena, Rodrigo (2019), "El 'periodismo de espectáculos”, en La Prensa, 2 de junio de 2019, México, disponible en: https://www.la-prensa.com.mx/analisis/el-periodismode-espectaculos-3705076.html

Diario Oficial de la Federación (DOF) (2020a), Constitución Política de los Estados Unidos Mexicanos, México, Cámara de Diputados del H. Congreso de la Unión, disponible en: http://www.diputados.gob.mx/LeyesBiblio/ref/cpeum.htm

Diario Oficial de la Nación (DOF) (2020b), Código Penal Federal, México, Cámara de Diputados del H. Congreso de la Unión, disponible en: http:/www.ordenjuridico.gob.mx/ Documentos/Federal/pdf/wo83048.pdf

Fromm, Erich (1992), El corazón del hombre. Su potencia para el bien y para el mal, México, FCE.

Gadea Aldave, Gilda (2015), "El terrorismo, las nuevas tecnologías y la libertad de expresión en España", Revista Pensamiento Penal, núm. 12, pp. 78-100, disponible en: http:// www.pensamientopenal.com.ar/system/files/2016/04/doctrina42689.pdf

Gamboa Montejano, Claudia y Arturo Ayala Cordero (2007), Derecho de la intimidad y el honor vs. derecho a la información. Estudio teórico conceptual, marco jurídico a nivel federal y estatal e iniciativas presentadas en la materia en la LIX Legislatura, México, Cámara de Diputados del H. Congreso de la Unión. LX Legislatura, disponible en: http://www. diputados.gob.mx/sedia/sia/spi/SPI-ISS-01-07.pdf

García Fernández, Dora (2011), "El derecho a la intimidad del paciente y el secreto profesional de los profesionales de la salud", Etbio, año 1, núm. 2, pp. 25-42.

Gobierno del Estado de México (GEM) (2021), Código Penal del Estado de México, en Gaceta del Gobierno, 27 de agosto de 2021, Toluca, disponible en: https://legislacion.edomex. gob.mx/sites/legislacion.edomex.gob.mx/files/files/pdf/cod/ vig/codvig006.pdf

Instituto de Investigaciones Jurídicas (s/f), Marco jurídico de la libertad de expresión en México, México, UNAM, disponible en: https://archivos.juridicas.unam.mx/www/bjv/ libros/6/2583/8.pdf

Jiménez Quezada, Yuliana (2018), Identificación imaginaria, simbólica o fantasmática en adolescentes que extiman en $\mathrm{Fa}$ cebook, [Tesis de licenciatura], Universidad Autónoma del Estado de México, disponible en: http://ri.uaemex.mx/ handle/20.500.11799/98766

Martínez Sánchez, Omar Raúl (2016), Ética y autorregulación periodísticas en México. Conceptualización, historia, retos y documentos, México, Comisión de Derechos Humanos del Distrito Federal, disponible en: https://cdhcm.org.mx/wpcontent/uploads/2015/06/etica-y-autorregulacion.pdf

Millán Martínez, Amada María Fernanda (2017), "Narcoseries-apología del delito", en Memoria del 5 Congreso Estudiantil de Investigación del Sistema Incorporado, México, UNAM, pp. 1-11, disponible en: http://vinculacion.dgire. unam.mx/vinculacion-1/Memoria-Congreso-2017/trabajos-ciencias-sociales/derecho/3.pdf

Murcia González, Vivian (2010), "Calidad periodística en la revista TVyNovelas" [Artículo especializado de grado presentado como requisito para optar al título de periodista], Universidad del Rosario, disponible en: https://repository. urosario.edu.co/handle/10336/1845

Office of the High Commissioner for Human Rights (UN Human Rights) (1948), Declaración Universal de Derechos 
Humanos, disponible en: https://www.ohchr.org/en/udhr/ pages/Language.aspx?LangID $=$ spn

Office of the High Commissioner for Human Rights (UN Human Rights) (1966), Pacto Internacional de Derechos Civiles y Políticos, disponible en: https:/www.ohchr.org/sp/professionalinterest/pages/ccpr.aspx

Organización de los Estados Americanos (OEA) (1969), Convención Americana sobre Derechos Humanos (Pacto de San José), Columbia, Organización de los Estados Americanos, disponible en: https://www.oas.org/dil/esp/tratados b-32 convencion_americana_sobre_derechos_humanos. $\bar{h}$ tm

Pérez Fernández, Francisco (2004), "El medio social como estructura psicológica. Reflexiones a partir del modelo ecológico de Bronfenbrenner", EduPsykhé, vol. 3, núm. 2, pp. 161-177, disponible en: file://C:/Users/Usuario2/AppData/Local/Temp/Dialnet-ElMedioSocialComoEstructuraPsicologica-1071166.pdf

Pfeffer Urquiaga, Emilio (2000), "Los derechos a la intimidad o privacidad, a la honra y a la propia imagen. Su protección frente a la libertad de opinión e información", Ius et Praxis, vol. 6, núm. 1, pp. 465-474, disponible en: https://www. redalyc.org/articulo.oa? id $=19760123$

Psicoterapeutas.com (2016), "Criterios del DSM-5 para el trastorno por estrés postraumático (TEPT)", Madrid, Psicoterapeutas.com, disponible en: http://www.psicoterapeutas. com/pacientes/DSM5_criterios_TEPT.html

Ramírez Aguilar, Sofía, Leonor Ortiz Monasterio, Leonardo Núñez González et al. (2019), "Anuario de la corrupción 2019”, en Nexos, 1 de diciembre de 2019, México, disponible en: https:/www.nexos.com.mx/?p=45975

Rivera Rogel, Diana, Xosé Pereira-Fariña y Jenny Yaguache Quichimbo (2015), "Rutinas de producción informativa en los ciberdiarios de referencia de Ecuador: El Universo, El Mercurio, El Diario y Crónica de la Tarde", Revista Latina de Comunicación Social, núm. 70, pp. 14-27, disponible en: file://C:/Users/Usuario2/AppData/Local/Temp/DialnetRutinasDeProduccionInformativaEnLosCiberdiariosDeR-4916656.pdf

Roldán, Itzel (2019), "Los escándalos más virales del 2019: divorcios, bodas, peleas y más", en Vanguardia MX, 28 de diciembre de 2019, Coahuila, disponible en: https:/vanguardia.com.mx/articulo/los-escandalos-mas-virales-del2019-divorcios-bodas-peleas-y-mas

S Moda (2019), "Ocho escándalos sexuales que marcaron un antes y un después en la vida de los famosos", en S Moda, 4 de agosto de 2019, Madrid, disponible en: https:// smoda.elpais.com/celebrities/escandalos-sexuales-famosos/100296070/image/100296078

Sánchez-Ostiz, Pablo (2006), "La apología del delito", Persona y Derecho, vol. 55, pp. 619-652, disponible en: https://dadun. unav.edu/handle/10171/14691

Stange Marcus, Hans y Claudio Salinas Muñoz (2009), Rutinas periodísticas. Discusión y trayectos teóricos sobre el concepto y su estudio en la prensa chilena, Santiago de Chile, Universidad de Chile.

Tello Díaz, Lucía (2013), "Intimidad y «extimidad» en las redes sociales. Las demarcaciones éticas de Facebook", Comunicar, vol. XXI, núm. 41, pp. 205-213, disponible en: https:// www.revistacomunicar.com/index.php?contenido=detall es\&numero $=41 \&$ articulo $=41-2013-20$

Torrico Linares, Esperanza, Carmen Santín Vilariño, Monserrat Andrés Villas et al. (2002), "El modelo ecológico de
Bronfrenbrenner como maco teórico de la Psicooncología”, Anales de Psicología, vol. 18, núm. 1, junio, pp. 45-59, https://www.um.es/analesps/v18/v18_1/03-18_1.pdf

United Nations Educational, Scientific and Cultural Organization (UNESCO) (1983), Código internacional de ética periodística, París, UNESCO, disponible en: http://www.cca. org.mx/ps/lideres/cursos/platino 4/html/m6/t4/UNESCOcodigU.pdf

Villalpando, Waldo (coord.) (2005), Hacia un Plan Nacional contra la Discriminación. La discriminación en Argentina. Diagnóstico y propuestas, Buenos Aires, Instituto Nacional contra la Discriminación, la Xenofobia y el Racismo, disponible en: https://www.conapred.org.mx/index.php?cont enido $=$ documento\&id $=67$ \&id_opcion $=150 \&$ \&op $=150$

Yelo Díaz, María Soledad (2004), Las rutinas informativas en la construcción de la actualidad, [Memoria para optar por el grado de doctor], Universidad Complutense de Madrid, disponible en: https://eprints.ucm.es/5167/

Leonor Guadalupe Delgadillo Guzmán. Doctora en Ciencias Sociales por el Colegio Mexiquense, México; Maestra en Psicología Clínica por la Universidad Autónoma del Estado de México (UAEM), México; especialista en Intervención Clínica Psicoanalítica por la UAEM, psicóloga por la Universidad Nacional Autónoma de México (UNAM), México. Licenciada en Derecho y Maestra en Derecho Procesal por el IULATAM, México. Actualmente, estudia el doctorado en Derecho. Profesora investigadora de la Facultad de Ciencias de la Conducta de la UAEM. Líder del cuerpo académico consolidado Vulnerabilidad, Educación y Sustentabilidad. Miembro del Sistema Nacional de Investigadores, nivel I. Ha colaborado con la administración pública en proyectos a nivel federal y estatal. Su agenda de estudio se enfoca en el desarrollo de investigaciones en materia de vulnerabilidad y violencia con enfoque en los derechos humanos y la perspectiva de género. Autora de artículos, capítulos, libros, conferencista a nivel local, nacional e internacional. Acreedora de diferentes distinciones. Activista en contra de la violencia microsocial, fundadora del colectivo Juntos por un mejor presente, A.C. y del Voluntariado de Colonos de Misiones de Santa Esperanza. Entre sus últimas publicaciones se encuentran: "La progresividad en la protección y el ejercicio de los derechos sexuales, el caso de la orientación sexual y la identidad de género" (2019); "Evaluación del dominio de los límites corporales en menores de edad" (en Tópicos en Educación y Humanidades, 2019); y "Medición de la violencia laboral a través de una escala psicométrica (Evil-Ad)" (en Psicología organizacional en Latinoamérica, 2018). 


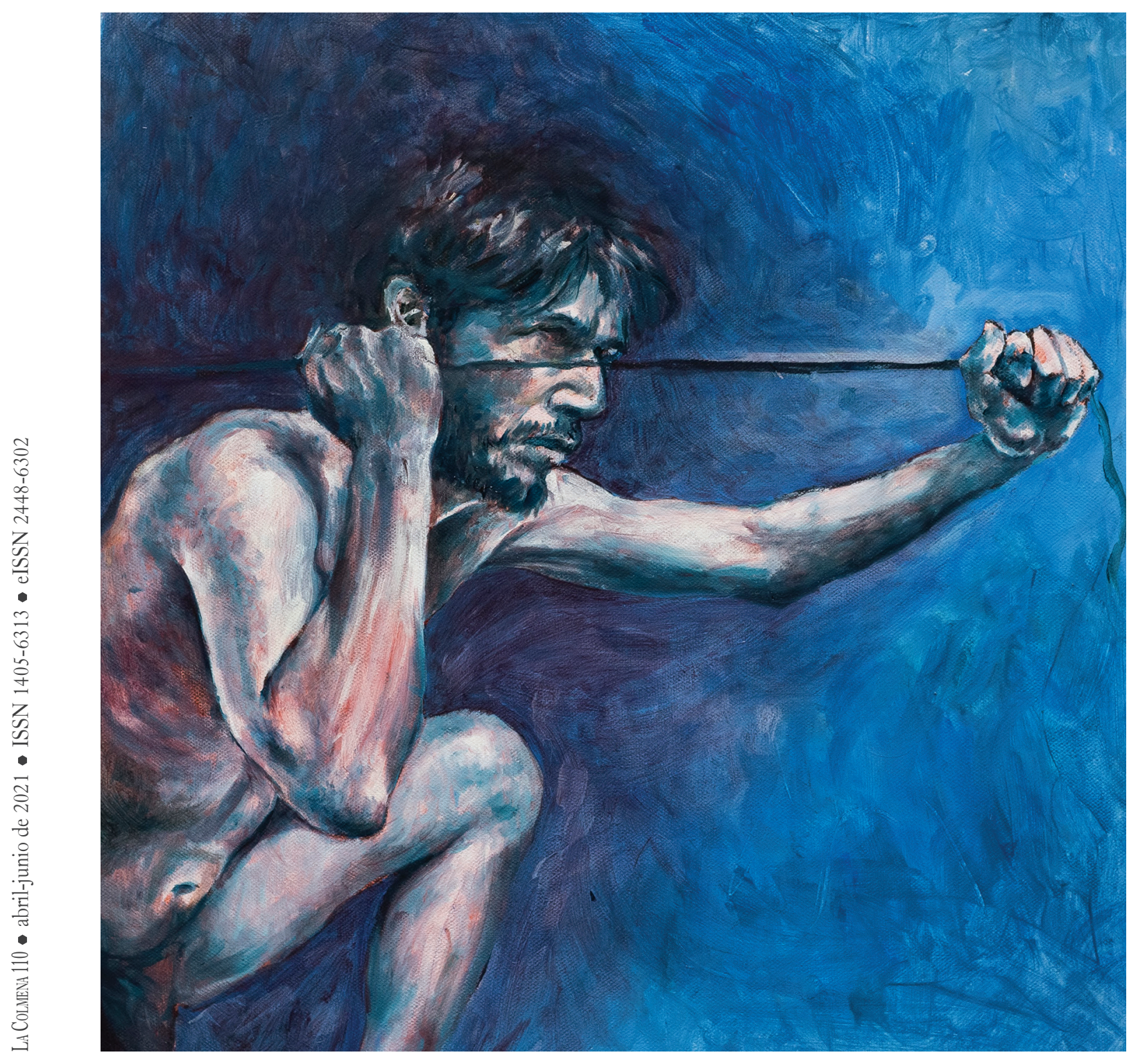

Resistencia superficial, de la serie Mar incendiado (2021). Óleo sobre lino: Xilberto Loera-Núñez. Prohibida su reproducción en obras derivadas. 